\title{
Diagnosis of Cylindrocarpon destructans Using Enzyme-Linked Immunosorbent Assay
}

*Co-corresponding authors J. Lee

Tel: $+82-51-200-7554$

Fax: $+82-51-200-7505$

E-mail: jungle@dau.ac.kr

S.-H. Lee

Tel: +82-43-871-5609

E-mail: Ish750409@korea.kr

Received July 11, 2019

Accepted August 30, 2019

\author{
Taiying $\mathrm{Li}^{1}$, Sungyeon $\mathrm{Ji}^{1}$, Boknam Jung ${ }^{2}$, Bo Yeon Kim ${ }^{1}$, Kwang Sik Lee ${ }^{1}$, Mun \\ Won $\mathrm{Seo}^{3}$, Sung Woo Lee ${ }^{3}$, Jungkwan Lee ${ }^{1 *}$, and Seung-Ho Lee \\ 'Department of Applied Biology, Dong-A University, Busan 49315, Korea \\ ${ }^{2}$ Forest Insect Pests and Diseases Division, National Institute of Forest Science, Seoul 02455, Korea \\ ${ }^{3}$ Ginseng Research Division, National Institute of Horticultural and Herbal Science, Eumseong 27715, \\ Korea
}

\begin{abstract}
Cylindrocarpon destructans causes ginseng root rot and produces radicicol that has an antifungal effect. In this study, we developed a method to detect this fungus using enzyme-linked immunosorbent assay (ELISA). Secreted proteins of $C$. destructans were used as antigens to obtain $C$. destructans-specific lgG from mouse. Out of 318 monoclonal antibodies generated from mouse, two antibodies ( $C d 7-2-2$ and Cd7-2-10) showed highest specificity and sensitivity. Indirect ELISA using both antigens successfully detected C. destructans in soils, but direct ELISA using lgG conjugated with horseradish peroxidase failed to detect antigens in soils. The indirect ELISA developed here can efficiently detect the fungus and help manage ginseng root rot disease in fields.
\end{abstract}

Keywords: Cylindrocarpon destructans, Diagnosis, Enzyme-linked immunosorbent assay, Fusarium solani, Ginseng root rot
Ginseng (Panax ginseng C. A. Meyer) is a medicinal crop that has been widely cultivated in Asia because of its excellent active ingredients for human health. Recently, the use of ginseng has been expanded into various fields including functional foods and cosmetics. The demand for ginseng has been increasing, but the production is not increasing because it usually takes 4 to 6 years for ginseng cultivation and various fungal pathogens threaten the ginseng production (Shin et al., 2012). Among the diverse ginseng pathogens, the ascomycete fungus Cylindrocarpon destructans is the most destructive pathogen and causes ginseng root rot (Chung, 1975; Farh et al., 2017; Reeleder and Brammall, 1994). This fungus survives for long time in the form of chla-

Research in Plant Disease

pISSN 1598-2262, elSSN 2233-9191

www.online-rpd.org mydospores, and causes ginseng root rot under favorable condition for disease development (Chung, 1975; Kang et al., 2016).

Rapid and accurate diagnosis of plant pathogens is important for correct disease control. Currently, the methods using nested-polymerase chain reaction (PCR) and real time-PCR are available for the diagnosis of ginseng root rot (Doh, 2003; Jang et al., 2005; Kang et al., 2014). Although these methods are effective in diagnosing $C$. destructans, they require equipment and specific techniques. One of the more rapid diagnostic techniques for field application is a kit based on enzyme-linked immunosorbent assay (ELISA). It analyzes the presence or quantity of pathogens by enzyme reaction in field even without the use of a special device. Diagnostic kits have been developed in various fields such as detection of insecticides and mycotoxins as well as the diagnosis of pathogenic bacteria, fungi, and viruses (Kang et 
al., 2010; Lin, 2015; Ming et al., 2019).

Previously, we developed a selective medium for C. destructans using radicicol which is produced by this fungus and has an antifungal effect against various soil-borne fungi (Kang et al., 2014). Addition of radicicol into medium suppressed the growth of other fungi and resulted in the isolation of $C$. destructans from soil and diseased ginseng. From the results, we hypothesize that $C$. destructans secretes proteins into the selective medium and we can generate antibodies binding to the secreted proteins. Based on this hypothesis, we generated monoclonal antibodies for the secreted proteins and developed a new diagnosis tool for this fungus in this study.

Cylindrocarpon destructans (KACC 41077) was obtained from the Korean Agricultural Culture Collection (Jeonju, Korea) and Fusarium solani 13chu01-05 was isolated from ginseng with root rot symptom. The $F$. solani strain was used as a negative control to isolate antibodies specific to C. destructans. C. destructans and F. solani strains were cultured for 7 days in complete media (Leslie and Summerell, 2006) at $20^{\circ} \mathrm{C}$ and $25^{\circ} \mathrm{C}$, respectively. Three mycelial blocks (diameter: $5 \mathrm{~mm}$ ) from the growing margins were subcultured in 100-ml minimal medium (MM) (Leslie and Summerell, 2006) for 7 days in an orbital shaker (200 rpm). Mycelia were harvested through filter paper and washed twice with sterile water. The washed mycelia were additionally incubated for $24 \mathrm{hr}$ in 100-ml MM with 5\% methanol for antigen preparation.

The culture was centrifuged $\left(8,000 \times g, 10 \mathrm{~min}, 4^{\circ} \mathrm{C}\right)$ and the supernatant filtered through a filter system with $0.22-\mu \mathrm{m}$ pore size for protein purification. Proteins were extracted by modifying the existing TCA-acetone method (Mechin et al., 2007). In brief, the filtered supernatant (50 ml) was combined with $200 \mathrm{ml}$ of $12.5 \%$ acetone with $0.07 \%$ $\beta$-mercaptoethanol (Sigma-Aldrich, St. Louis, MO, USA) and placed in $-20^{\circ} \mathrm{C}$ for $24 \mathrm{hr}$. The solution was centrifuged $\left(8,000 \times g, 10 \mathrm{~min}, 4^{\circ} \mathrm{C}\right)$ and the supernatant discarded. The pellet suspended with $5 \mathrm{ml}$ of $12.5 \%$ aceton with $0.07 \%$ $\beta$-mercaptoethanol and centrifuged again $(8,000 \times g, 10 \mathrm{~min}$, $4^{\circ} \mathrm{C}$ ). The supernatant discarded and the pellet dissolved in $1 \mathrm{ml}$ of $80 \%$ acetone with $0.07 \% \beta$-mercaptoethanol. The solution placed in ice and sonicated for $90 \mathrm{sec}(5 \mathrm{sec}$, run; 2 $\mathrm{sec}$, rest) then centrifuged $\left(13,000 \times \mathrm{g}, 5 \mathrm{~min}, 4^{\circ} \mathrm{C}\right)$ and supernatant discarded. The pellet dissolved in $1 \mathrm{ml}$ of phosphate buffered saline (Sigma-Aldrich) and stored at $-20^{\circ} \mathrm{C}$.
Monoclonal antibody production was conducted by Post-Bio (Hanam, Korea). Secreted proteins $(2.3 \mathrm{mg} / \mathrm{ml})$ purified above were injected into mice (every 2 months) and splenocytes were isolated to fuse with myeloma cells. Positive clones were selected and each fusion cell was massively cultured to obtain monoclonal antibodies. In total, 318 monoclonal antibodies were prepared from hybridoma, and 16 out of them were specific to $C$. destructans but not to $F$. solani. For sensitivity test, supernatant containing secreted proteins of $C$. destructans was diluted 10 to $10^{4}$ times with MM and used as antigens for indirect ELISA as previously described (Lin, 2015). Two antibodies, Cd7-2-2 and Cd7-2-10, showed both high sensitivity and specificity (Table 1), and were selected for further experiment.

The maximum sensitivity of two antibodies were tested using ELISA Starter Accessory Kit (E101, Bethyl, Montgomery, TX, USA). In brief, antigen ( $1.78 \mu \mathrm{g} / \mathrm{ml}$ of secreted proteins) was diluted 10 to $10^{4}$ times with MM and 10- $\mu$ l diluent was supplied with 90- $\mu \mathrm{l}$ Coating buffer then incubated in 96 wells for $60 \mathrm{~min}$. After washing 3 times, $200 \mu$ of Blocking solution was added to each well and incubated for $30 \mathrm{~min}$. Blocking solution was removed and $100 \mu$ of 10 to $10^{4}$ times diluted monoclonal antibody was added to each well then incubated for $60 \mathrm{~min}$. Each well was washed 3 times and $100 \mu$ l of 5,000 times diluted Goat anti-mouse lgG (Enzo Life Sciences, Farmingdale, NY, USA) was added to each well then incubated for $60 \mathrm{~min}$. After incubation, each well was washed 5 times. Then $100 \mu \mathrm{l}$ of 3,3',5,5'-tetramethylbenzidine substrates was added to each well for 5-min reaction, which was stopped using $2 \mathrm{M} \mathrm{H}_{2} \mathrm{SO}_{4}$. The absorbance of each well was determined using microtiter plate reader at $415 \mathrm{~nm}$. Cd7-2-2 showed sensitivity to antigen even thought it was diluted $10^{3}$ times, and $10^{4}$ times diluted antibody also showed sensitivity to 10 times diluted antigen (Fig. 1A). On the other hand, Cd72-10 showed sensitivity to $10^{2}$ times diluted antigen, and $10^{4}$ times diluted antibody showed sensitivity to 10 times diluted antigen (Fig. 1B). Although there was abnormal absorbance variations in several tested wells, the results offer the possibility that these two antibodies could be used to detect C. destructans in soil. Addition of two antibodies together resulted in higher absorbance than the single antibody was binding to antigens (Fig. 2), suggesting that the epitopes of Cd7-2-2 and Cd7-2-10 bind to different antigens. In addition, these two antibodies were not binding to secreted proteins purified from $F$. solani, showing that they are specific to $C$. 
Table 1. Absorbance of antibodies with antigen dilution in indirect enzyme-linked immunosorbent assay

\begin{tabular}{|c|c|c|c|c|c|c|}
\hline \multirow{2}{*}{ Antibody No. } & \multicolumn{5}{|c|}{ Dilution ratio of antigen $^{\mathrm{a}}$} & \multirow{2}{*}{ Control $^{b}$} \\
\hline & 1 & $10^{1}$ & $10^{2}$ & $10^{3}$ & $10^{4}$ & \\
\hline Cd7-2-2 & 0.661 & 0.127 & 0.020 & 0.010 & 0.000 & 0.007 \\
\hline Cd7-2-10 & 0.633 & 0.143 & 0.019 & 0.010 & 0.010 & 0.011 \\
\hline Cd7-2-6 & 0.700 & 0.141 & 0.023 & 0.011 & 0.012 & 0.007 \\
\hline $\mathrm{Cd} 7-2-26$ & 0.731 & 0.129 & 0.014 & 0.002 & 0.003 & 0.006 \\
\hline Cd7-2-22 & 0.654 & 0.131 & 0.013 & 0.003 & 0.002 & 0.008 \\
\hline Cd12-1-46 & 0.639 & 0.041 & 0.001 & 0.000 & 0.002 & 0.008 \\
\hline Cd7-2-18 & 0.728 & 0.126 & 0.012 & 0.003 & 0.006 & 0.022 \\
\hline Cd66 & 0.796 & 0.101 & 0.001 & 0.000 & 0.006 & 0.022 \\
\hline Cd7-2-61 & 0.673 & 0.144 & 0.017 & 0.005 & 0.015 & 0.048 \\
\hline Cd96 & 0.613 & 0.148 & 0.017 & 0.008 & 0.015 & 0.015 \\
\hline Cd95 & 0.644 & 0.102 & 0.006 & 0.002 & 0.000 & 0.021 \\
\hline Cd7-2-64 & 0.661 & 0.126 & 0.009 & 0.247 & 0.006 & 0.013 \\
\hline Cd12-1-34 & 0.537 & 0.043 & 0.000 & 0.000 & 0.001 & 0.011 \\
\hline Cd7-2-4 & 0.619 & 0.130 & 0.008 & 0.002 & 0.003 & 0.012 \\
\hline Cd7-2-32 & 0.664 & 0.133 & 0.013 & 0.002 & 0.244 & 0.007 \\
\hline Cd7-2-62 & 0.649 & 0.137 & 0.014 & 0.005 & 0.006 & 0.017 \\
\hline
\end{tabular}

${ }^{a}$ Supernatant of Cylindrocarpon destructans culture was diluted using minimal medium.

${ }^{\mathrm{b}} \mathrm{Supernatant}$ of Fusarium solani culture.

A

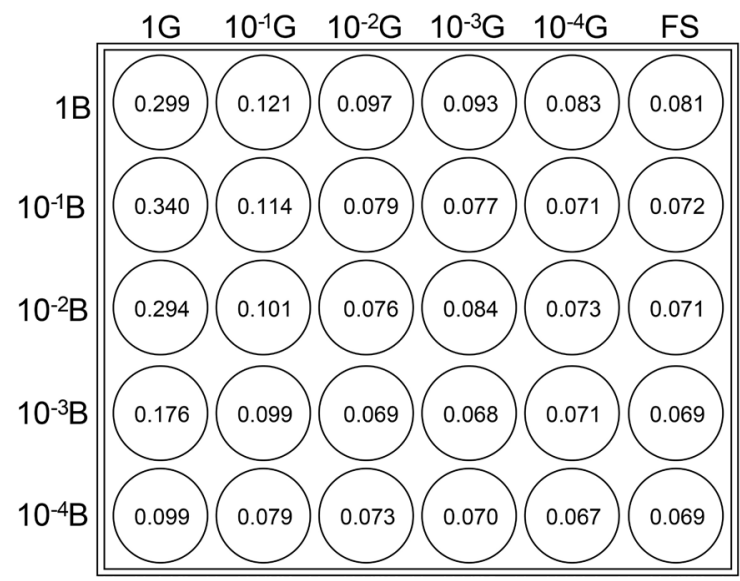

B

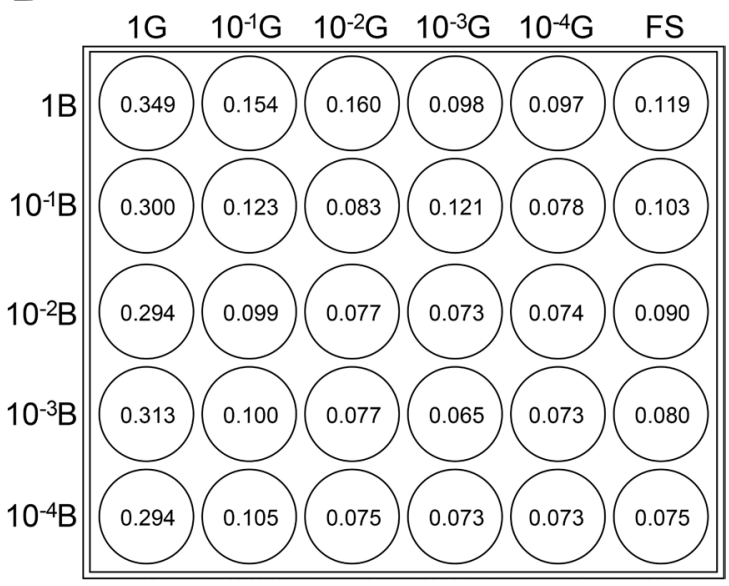

Fig. 1. Absorbance in indirect enzyme-linked immunosorbent assay using the monoclonal antibodies, Cd7-2-2 (A) and Cd7-2-10 (B). Cylindrocarpon destructans and Fusarium solani was cultivated in minimal medium (MM) and the cultures filtered through a filter system with $0.22-\mu \mathrm{m}$ pore size. The supernatant was diluted 10 to $10^{4}$ times using $\mathrm{MM}$ and monoclonal antibodies were diluted 10 to $10^{4}$ times using distilled water. G, antigen; B, antibody; FS, supernatant of F. solani.

destructans.

ELISA is widely used for antigen-antibody immune response. Particularly, horseradish peroxidase (HRP) is a stable protein and is useful for confirming the reaction of enzymes (Chevrier et al., 2004; Kassim et al., 2013). We also conjugated the Cd7-2-2 with HRP and tried to develop direct ELISA 


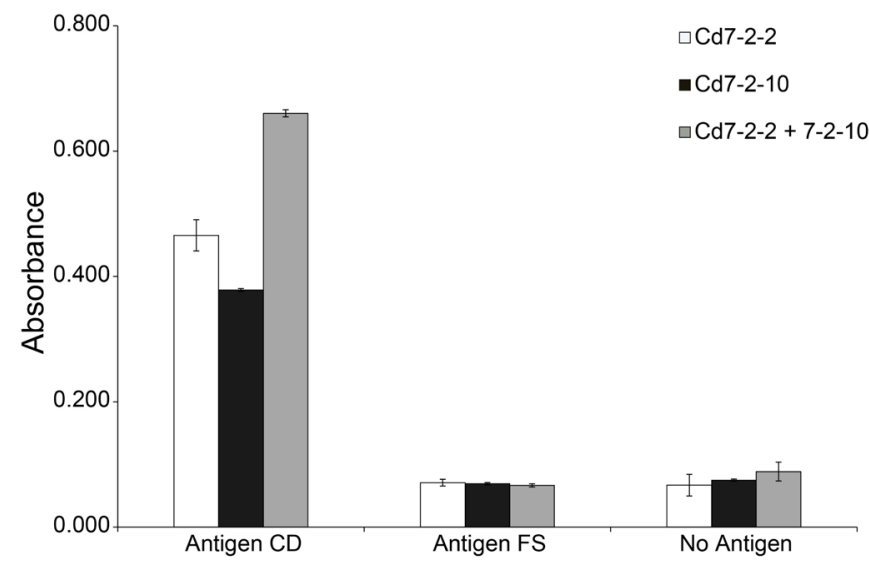

Fig. 2. Antibodies epitope test against antigen with indirect enzyme-linked immunosorbent assay. The absorbance was observed at $415 \mathrm{~nm}$. Antigen CD, supernatant of Cylindrocarpon destructans; Antigen FS, supernatant of $F$. solani; No Antigen, minimal medium.
A

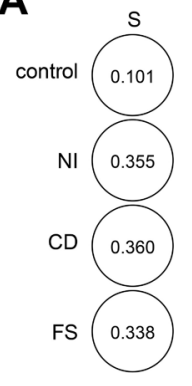

B

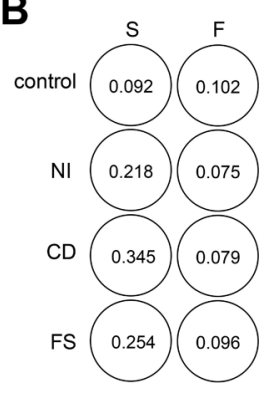

C

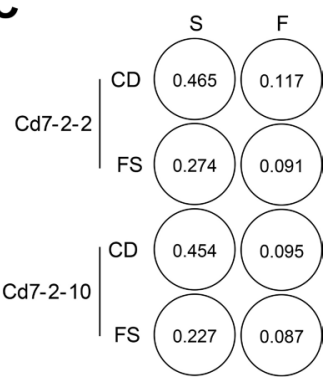

Fig. 3. Absorbance of soil cultures inoculated with either Cylindrocarpon destructans and Fusarium solani. (A) Absorbance in direct enzyme-linked immunosorbent assay (ELISA) using Cd7-2-2 horseradish peroxidase conjugate. (B) Absorbance in indirect ELISA using the monoclonal antibody Cd7-2-2. (C) Absorbance in indirect ELISA using the monoclonal antibodies. Control, minimal medium; $\mathrm{NI}$, cell free soil; $\mathrm{CD}$, soil inoculated with $C$. destructans; FS, soil inoculated with F. solani; S, soil culture; F, soil-free culture.

which is simpler than indirect ELISA. Cd7-2-2 HRP conjugate showed specific to $C$. destructans but not to F. solani. The application of the Cd7-2-2 HRP conjugate was tested on soil samples. To do it, C. destructans $\left(1.1 \times 10^{5}\right.$ colony-forming unit [CFU]) and F. solani (1.0 $\left.\times 10^{7} \mathrm{CFU}\right)$ were inoculated in soils $(100 \mathrm{~g})$, respectively. The soil was incubated in $50 \mathrm{ml}$ of selective medium (Kang et al., 2014). The culture was coated on well for direct ELISA and the antibodies were applied onto the well. Unfortunately, Cd7-2-2 HRP conjugants were nonspecifically binding to soil even though any antigens were absent in soil (Fig. 3A). The monoclonal antibody Cd7-22 was also non-specifically binding to soil but the reaction disappeared in soil-free solution (Fig. 3B). The absorbance values were clearly different between soil inoculated with either C. destructans or F. solani (Fig. 3C), indicating it is suitable for detection of antigens in soil. We expect that the currently identified antibodies can be applied for the use of gold-nano particles to detect this fungus in soils and diseased ginseng, and further we will focus on the development of detection methods for farmers to use it in fields.

\section{Conflicts of Interest}

No potential conflict of interest to this article was reported.

\section{Acknowledgements}

This work was supported by the Rural Development Administration (PJ012435).

\section{References}

Chevrier, M.-C., Châteauneuf, I., Guérin, M. and Lemieux, R. 2004. Sensitive detection of human IgG in ELISA using a monoclonal anti-lgG-peroxidase conjugate. Hybrid. Hybridomics 23: 362-367.

Chung, H. S. 1975. Studies on Cylindrocarpon destructans (Zins.) Scholten causing root rot of ginseng. Rep. Tottori Mycol. Inst. 12: 127-138.

Doh, E.-S. 2003. Development of RT-PCR kit for diagnosis of pathogenic agent of ginseng root rot in the ginseng field. Korean $\mathrm{J}$. Plant Resour. 16: 40-48. (In Korean)

Farh, M. E.-A., Kim, Y.-J., Kim, Y.-J. and Yang, D.-C. 2017. Cylindrocarpon destructans/ Ilyonectria radicicola-species complex: causative agent of ginseng root-rot disease and rusty symptoms. J. Ginseng Res. 42: 9-15.

Jang, C.-S., Lee, J.-J., Kim, S.-I., Song, J.-Y., Yoo, S.-J. and Kim, H.-G. 2005. Specific detection of root rot pathogen, Cylindrocarpon destructans, using nested PCR from ginseng seedlings. Res. Plant Dis. 11: 48-55. (In Korean)

Kang, W. M., Yang, J. H., Jang, W. W., Son, S. W., Yoon, S. H., Hwang, K. K. et al. 2010. Development of immunoassay kits for the detection of Paenibacillus larvae infection in honeybee. Korean J. Apic. 25: 105-114. (In Korean)

Kang, Y., Kim, M. R., Kim, K. H., Lee, J. and Lee, S. H. 2016. Chlamydospore induction from conidia of Cylindrocarpon destructans isolated from ginseng in Korea. Mycobiology 44: 63-65.

Kang, Y., Lee, S.-H. and Lee, J. 2014. Development of a selective medium for the fungal pathogen Cylindrocarpon destructans using radicicol. Plant Pathol. J. 30:432-436.

Kassim, N., Mtenga, A. B., Shim, W.-B. and Chung, D.-H. 2013. Pro- 
duction of mouse anti-quail $\lg \mathrm{Y}$ and subsequent labeling with horseradish peroxidase using cyanuric chloride. J. Microbiol. Biotechnol. 23: 527-533.

Leslie, J. F. and Summerell, B. A. 2006. The Fusarium Laboratory Manual. Blackwell Publishing, Ames, IW, USA. 388 pp.

Lin, A. V. 2015. Indirect ELISA. Methods Mol. Biol. 1318: 51-59.

Méchin, V., Damerval, C. and Zivy, M. 2007. Total protein extraction with TCA-acetone. Methods Mol. Biol. 355: 1-8.

Ming, F., Cheng. Y., Ren, C., Suolang, S. and Zhou, H. 2019. Develop- ment of a DAS-ELISA for detection of H9N2 avian influenza virus. J. Virol. Methods 263: 38-43.

Reeleder, R. D. and Brammall, R. A. 1994. Pathogenicity of Pythium species, Cylindrocarpon destructans, and Rhizoctonia solani to ginseng seedlings in Ontario. Can. J. Plant Pathol. 16: 311-316.

Shin, J.-H., Yun, B.-D., Kim, H.-J., Kim, S.-J. and Chung, D.-Y. 2012. Soil environment and soil-borne plant pathogen causing root rot disease of ginseng. Korean J. Soil Sci. Fertil. 45: 370-376. (In Korean) 